\title{
REVIEW
}

\section{Recommendations for Providers on Person-Centered Approaches to Assess and Improve Medication Adherence}

\author{
Hayden B. Bosworth, PhD ${ }^{1,2,3}$, Stephen P. Fortmann, MD', Jennifer Kuntz', Leah L. Zullig, PhD ${ }^{1,3}$, \\ Phil Mendys, PharmD ${ }^{5,6}$, Monika Safford, MD ${ }^{7}$, Shobha Phansalkar, RPh, PhD ${ }^{8,9}$, Tracy Wang, MD ${ }^{10}$, \\ and Maureen $H$. Rumptz, $P h D^{4}$
}

\begin{abstract}
${ }^{1}$ Center for Health Services Research in Primary Care, Durham Veterans Affairs Medical Center, Durham, NC, USA; ${ }^{2}$ School of Nursing and Department of Psychiatry, Duke University Medical Center, Durham, NC, USA; ${ }^{3}$ Department of Medicine, Duke University Medical Center, Durham, NC, USA; ${ }^{4}$ Kaiser Permanente Center for Health Research, Portland, OR, USA; ${ }^{5}$ ffizer Inc. Medical Affairs, New York, NY, USA; ${ }^{6}$ UNC Division of Cardiology, Chapel Hill, NC, USA; ${ }^{7}$ Department of Medicine, University of Alabama at Birmingham, Birmingham, AL, USA; ${ }^{8} \mathrm{Innovation}$ and Clinical Informatics, Clinical Drug Information division of Wolters Kluwer Health, Department of General Medicine, Brigham and Women's Hospital and Harvard Medical School, Boston, MA, USA; ${ }^{9}$ Partners Healthcare, Boston, MA, USA; ${ }^{10}$ Division of Cardiology, Department of Medicine, Duke University Medical Center, Durham, NC, USA.
\end{abstract}

Medication non-adherence is a significant clinical challenge that adversely affects psychosocial factors, costs, and outcomes that are shared by patients, family members, providers, healthcare systems, payers, and society. Patient-centered care (i.e., involving patients and their families in planning their health care) is increasingly emphasized as a promising approach for improving medication adherence, but clinician education around what this might look like in a busy primary care environment is lacking. We use a case study to demonstrate key skills such as motivational interviewing, counseling, and shared decisionmaking for clinicians interested in providing patientcentered care in efforts to improve medication adherence. Such patient-centered approaches hold considerable promise for addressing the high rates of nonadherence to medications for chronic conditions.

KEY WORDS: person-centered approach; shared decision-making; nonadherence; clinician education; motivational interviewing.

$\mathrm{J}$ Gen Intern Med 32(1):93-100

DOI: $10.1007 / \mathrm{s} 11606-016-3851-7$

(c) Society of General Internal Medicine 2016

\begin{abstract}
A dherence to medications is often suboptimal-up to $50 \%$ of patients do not take their prescribed medication as recommended. ${ }^{1-4}$ Medication non-adherence is associated with adverse health outcomes as well as negative social and economic consequences. ${ }^{5-7}$ The problem of medication nonadherence is often multifaceted and multifactorial; in general, most conceptual models of medication non-adherence take an ecological perspective, and include patient factors (e.g., literacy, cognitive function), provider factors (e.g., complex regimens), social/community factors (e.g., access to providers and pharmacy), health care factors (e.g., interaction with healthcare system, trust, prior authorization, fragmentation), and policy implications (e.g., coverage of medication). ${ }^{8-10}$ Thus,
\end{abstract}

Published online September 6, 2016 to be effective, interventions designed to improve appropriate medication use must adopt a comprehensive approach, often combining numerous proven strategies. Several evidence reviews have identified interventions with modest effects in promoting both overall and condition-specific medication adherence. ${ }^{1-16}$ Given the complex, multifactorial cause of medication non-adherence, interventions can be similarly multifactorial and multi-level. In this paper we focus on the physician-patient level to furnish providers with a guide to applying adherence research in the clinical encounter.

Evidence increasingly demonstrates that adopting a personcentered approach for medication use that incorporates patient beliefs, preferences, goals, and barriers to medication-taking (e.g., cost, technological ability, concerns about medication prescribing and use) leads to better clinical outcomes. ${ }^{17,18}$ Clinicians are in a key position to elicit this information from patients and to incorporate it into medication-related decisions, thereby improving medication adherence rates. Person-centered care focuses on providing patients with greater choice, recognizing their roles as consumers of health care who know best their own beliefs and preferences. This care is meant to encourage value concordance-in this case, the match between the treatment that is selected and the treatment that is most desirable to the patient in terms of timing, duration of a therapy, or potential physical, emotional, and social effects. ${ }^{19}$ As payment and delivery system models evolve to hold healthcare organizations and clinicians accountable for poor patient outcomes and downstream costs (e.g., via bundled payments and accountable care organizations), there is an increasing business case and need to identify methods to improve medication adherence by including patient-centered care.

We seek to provide methods and tools that healthcare providers might use to advance communication with their patients and ultimately to improve appropriate medication use. To accomplish this, we explore how healthcare providers can partner with patients to improve adherence by using personcentered approaches - defined as those that consider the whole person ${ }^{20}$-including motivational interviewing, 
counseling, and shared decision-making. Using a case study, this paper demonstrates how these concepts can be operationalized.

\section{CLINICAL SCENARIO 1. INTRODUCTION}

Mrs. K. is a 55-year-old African-American woman with hypertension and diabetes who is visiting you (her provider) with a chief complaint of back pain. In addition, she reports not sleeping well and describes symptoms of depression. Her selfreported blood pressure values are consistently in the range of 142-155/83-91 mm Hg. Beyond treating her pain, you want to evaluate whether you should prescribe an anti-hypertensive medication. You also appreciate the impact of the depressive symptoms and lack of restful sleep as possible contributors to the patient presentation. Although she did not bring them to her appointment, Mrs. K. has been prescribed two medications for diabetes and is concerned about the cost. She voluntarily tells you that she takes her medicines exactly as instructed. She expresses hesitancy to take another medication because of her budget constraints. She is currently out of work, and cost issues are a concern. Taking her financial concerns into consideration, you provide guidance about her back pain, and ask her to return in 4 weeks and bring her medications.

\section{PERSON-CENTERED CARE}

Previous studies have found that patient engagement, involvement, and satisfaction with health care are improved with more informative communication. ${ }^{21,22}$ These issues often lie below the surface of healthcare encounters and treatment decisions by providers. However, merely informing patients of their options and providing evidence on risks and benefits does not necessarily lead to quality decisions. ${ }^{23}$ Providers must also set and manage expectations for the treatment plan and clarify objectives of therapy so that patients can gauge their ability to attain therapeutic goals. This dialogue can be limited due to time constraints during the clinical encounter; however, recent research indicates that such dialogue can often be completed efficiently and result in positive outcomes. ${ }^{7}$ Another barrier to dialogue may be a deficiency in medical training in patientcentered care or appropriate medication adherence assessment and implementation, or both.

To address the latter, there is a growing shift in medical education toward developing person-centered skill sets that help providers understand and manage varying levels of patient interest, knowledge, and health literacy. ${ }^{24,25}$ Once the provider has confirmed that patients understand their disease and have been offered options that they understand, the provider can help ensure that the patients' decisions reflect their goals and preferences. A key step is assessing whether the facts were received and understood. Decision quality reflects the extent to which patients are informed and understand their options, and importantly, that decisions made reflect their goals and preferences. ${ }^{26}$ With this transition in medical education, providers will likely benefit from learning new skills to improve communication with patients during visits. There are also resources available to support practicing physicians, such as ManagingYourMeds (available from http://managingyourmeds.org), which lists a number of promising medication adherence practices. In addition, below we highlight simple techniques for evaluating medication use and improving shared decision-making and counseling in the context of medication adherence.

\section{EVALUATING APPROPRIATE MEDICATION USE}

Providers and patients tend to overestimate medication adherence. ${ }^{27}$ Even if a patient appears to be responding to therapy, adherence may occur only immediately before a visit. Clinicians tend to assume that their patients are adhering to medications, and patients are reluctant to report non-adherence. There are several approaches for improving medication adherence assessment. One is to screen for missed appointments, as non-adherence to appointments is correlated with lower medication adherence rates, and may be the first sign of dropping out of care entirely. ${ }^{28}$ Assessing non-adherence requires nonjudgmental communication. A key validated question is, "Have you missed any pills in the past week?", and any indication of having missed one or more pills signals suboptimal adherence requiring further exploration. ${ }^{29}$ Compared with pill counts, asking non-responders about their medication adherence using this single question will detect $55 \%$ of those with less than $100 \%$ adherence. ${ }^{30}$ Another common assessment question which incorporates motivational interviewing and is generally more patient-centered is, "A lot of people find it difficult to take their pills $100 \%$ of the time. Tell me about your experience in the last week." Suboptimal adherence can be detected through review of fill dates and pill counts (asking patients to bring in their medication bottles is a good idea anyway). Another approach is to ask patients at what time during the day they take their medications and how they remember to do so (Clinical Scenario 2).

\section{CLINICAL SCENARIO 2. EVALUATION OF APPROPRIATE MEDICATION USE}

Mrs. K. returns to the clinic 4 weeks later. Her back pain has improved and she reports sleeping better at night. She is meeting with her clergy, and her depression is improving. Her blood pressure, however, remains above 150/100 mm Hg. You ask about her medications, and she shares that she has also been taking an anti-hypertensive medication "twice a day," in addition to the two diabetes medications she indicated in the first encounter. You ask her for clarification regarding what twice a day means for her; she shares that she takes both hypertension medications - in the morning (four pills in the morning). You acknowledge that this is one way to interpret 
what "twice a day" may mean, but you clarify that you would like her to take each hypertension medication two times each day, $12 \mathrm{~h}$ apart. You provide a schematic that highlights she should take each medication once in the morning and once in the evening. By engaging in a 2-min dialogue, you have uncovered a fundamental misunderstanding of her drug regimen.

\section{MOTIVATIONAL INTERVIEWING AND COUNSELING}

Motivational interviewing (MI) is a method for improving communication around medication adherence. ${ }^{31}$. MI is a collaborative, person-centered form of counseling to elicit and strengthen motivation for change by using open-ended questions, affirmative statements, and summarizing. Originally developed as a counseling method for substance abuse, MI was later expanded to behaviors associated with other illnesses. ${ }^{32-36}$ An example of an MI question technique may include, "What would be some ideas that may help you remember to take your hypertension medication?" MI is intended to help patients recognize and address their problems and enhance their perception of autonomy and treatment efficacy. ${ }^{34}$

MI has been shown to improve patients' general health status or well-being, promote physical activity, help develop healthier nutritional habits, and manage chronic conditions such as mental illness, hypertension, hypercholesterolemia, obesity, and diabetes. ${ }^{37-41}$ Randomized controlled trials have shown that brief MI training for clinicians is effective for improving patient medication adherence, especially if there is follow-up contact after an initial training, ${ }^{42,43}$ and even at low doses (i.e., two or three sessions). MI is effective as a pretreatment adjunct and as an approach for less motivated or prepared patients, and may be applied for a wide range of medications across diverse populations. ${ }^{11,44}$

Another communication technique that promotes patientcenteredness and helps guide medication-related discussions is a theory-based counseling model called the 5 A's. This model has been shown to be suitable for application in busy healthcare environments and does not require sophisticated skills or experience. ${ }^{45}$ The 5 A's include the following steps: 1) assess beliefs, behavior, and knowledge about their medication; 2) advise medication behavior change; 3) agree upon clear goals for medication use; 4) assist in addressing barriers and securing social support; and 5) arrange follow-up contact. ${ }^{46}$ Use of the $5 \mathrm{~A}$ 's is associated with change in health behaviors across diverse populations and health behaviors. ${ }^{47-}$ ${ }^{49}$ Because the 5 A's model covers the key elements of selfmanagement support, it presents a guiding conceptual framework for evaluating and implementing behavioral change counseling interventions in chronic disease management (Clinical Scenario 3). ${ }^{50}$ Thus, this framework could be easily adapted to facilitate a person-centered approach to address medication adherence.

\section{CLINICAL SCENARIO 3. INCORPORATING ASPECTS OF MOTIVATIONAL INTERVIEWING AND USE OF $5 A^{\prime} S^{45}$}

At her next visit, Mrs. K. again complains of back stiffness and not sleeping well. While these are the two most pressing issues from her perspective, you remain concerned about her hypertension. You provide new suggestions for relieving stiffness and discuss how increasing her physical activity may help with her pain, sleep, and blood pressure. You also will remain vigilant regarding her mood and previously reported symptoms of depression, as they may be related and may have an impact on her ability to follow a treatment plan. Mrs. K. indicates that she is open to trying some exercise-taking her dog for a walk in the morning. However, she is concerned that sometimes she is stiff in the morning. You explore barriers and facilitators that may impact her exercising and ask how confident she is that she can start out slowly and gradually increase her walking. You ask Mrs. K. to keep track of her weekly exercise and to try to walk every other day for a minimum of $15 \mathrm{~min}$. She agrees to contact you in 4 weeks regarding her exercise regimen and pain level.

You also assess Mrs. K.'s beliefs and barriers regarding the use of her anti-hypertensive medication. When you ask, "Have you missed any pills in the past week?", she indicates that she sometimes forgets to take her blood pressure medications and does not take them when she feels stressed. You review with Mrs. K. that high blood pressure is asymptomatic and that the medications work best when taken around the same time each day, and ask whether she has had any adverse effects with her blood pressure medications. If she experiences side effects, such as dizziness, you share with her what to do. You summarize the visit by saying that, with the goal of increasing her activity and taking her two blood pressure medications daily, you expect her pain to decrease and her blood pressure to improve. Mrs. K. will measure her blood pressure at home every other day for the next 4 weeks, and at the next visit you will reasses both her pain and blood pressure control.

To help remind her to take her medications, you ask Mrs. K. to name an activity that she does twice a day. Mrs. K. indicates that she brushes her teeth twice daily and that she will place her anti-hypertensive medication near her toothbrush.

\section{SHARED DECISION-MAKING TO OPTIMIZE MEDICA- TION USE}

Research studies have examined shared decision-making (SDM) for a variety of illnesses and disabilities, including treatment decisions related to cancer ${ }^{51}$, mental illness ${ }^{52}$, and substance abuse. ${ }^{53}$ Results have demonstrated that SDM leads to enhanced patient knowledge and patient satisfaction with treatment choices (Clinical Scenario 4). ${ }^{21,54,55}$ However, in studies that have examined actual provider-patient interactions, researchers found that healthcare professionals almost always fail to adequately educate patients and enlist them in a 
process that meets the criteria for fully informed decisionmaking. ${ }^{56,57}$ In a study of fully insured individuals, after adjusting for potential confounders including health literacy and education, patients' perceived lack of SDM was significantly associated with primary medication non-adherence (i.e., not filling a new prescription; $\mathrm{RR}=2.42, p<0.05$ ), early nonpersistence $(\mathrm{RR}=1.34, p<0.01)$, and new prescription medication gap (5\% greater gap in medication supply, $p<0.01){ }^{58}$

The benefits of SDM include incorporating evidence and patient preferences into a consultation; improving patient knowledge, risk perception accuracy, and patient-clinician communication; and reducing decisional conflict, feeling uninformed, and inappropriate use of tests and treatments. ${ }^{59}$ SDM frames health decisions as an exchange between patient and healthcare provider with key components. ${ }^{53,60}$ Components of SDM include joint identification of the advantages and disadvantages of a specific issue by the patient and provider, and the provision of education about the illness and corresponding treatments. Thus, SDM is a process in which patients can express their preferences and goals, and reach an agreement with their provider regarding the treatment decision. ${ }^{61} \mathrm{MI}$ and SDM are complementary approaches.

SDM is not a single step within a consultation, but rather a social exchange that utilizes counseling skills to enhance engagement and guide decisions about treatments. Elements of SDM that providers employ include defining and explaining the problem; presenting options; discussing pros and cons (e.g., benefits, risks, costs); ascertaining a patient's values and preferences; exploring the patient's self-efficacy; offering recommendations; checking and clarifying patient understanding; moving or deferring a decision, if needed; and arranging follow-up. ${ }^{53,60}$ Various channels have been used to supplement this information exchange beyond direct patientprovider interactions, with Internet applications (e.g., SDM aids or tools) and social networks being especially promising innovations. ${ }^{62}$ While this may be difficult to accomplish in a typical clinical encounter, decision aids can be accessed outside of the clinical encounter, and additional support from the provider team may need to be considered.

SDM is a key element of successful medication adherence, but the prospect of long conversations may be daunting to providers with limited time per visit. However, as pointed out in a recent paper examining the 12 common myths of $\mathrm{SDM}^{63}$ it does not necessarily result in more time per consultation. In fact, a 2014 Cochrane review analyzed 115 decision aids, ${ }^{64}$ and among the ten papers that measured consultation length, two found that SDM took longer, one found that it took less time, and six found no statistically significant difference in consultation time. ${ }^{64}$ Furthermore, training physicians in communication skills results in substantial and significant improvements in patient adherence; one study showed that the odds of patient adherence were 1.62 times higher with physician communication training than without. ${ }^{65}$ The principle of reaching common ground may allow providers to use their time with patients more efficiently.
SDM usually occurs within the physician-patient dyad; however, there are several advantages to engaging interprofessional teams (e.g., including different members of the healthcare system) in SDM. Interdisciplinary teams may contribute different knowledge and skills to the decision-making process, thus producing more feasible and sustainable decisions. ${ }^{65}$ From the patient's standpoint, an interprofessional (IP) approach to SDM may increase the likelihood of patient participation in decision-making and support agreement regarding a healthcare treatment. ${ }^{66,67}$ Such interventions could also improve the decisions made by patients and their healthcare teams by fostering integrated healthcare services and continuity of care ${ }^{68}$, and as a result, they could better match what patients request to what they receive. A Cochrane review suggests that practice-based IP collaborative interventions can improve healthcare processes and outcomes. ${ }^{69}$

\section{CLINICAL SCENARIO 4. SHARED DECISION-MAKING}

You have already elicited from Mrs. K. that her primary concern is her back pain, which makes looking for work difficult. She remains depressed and describes financial hardship in paying for her medications. You are concerned because her blood pressure is running higher than when you saw her 6 months ago. You realize that your goal of blood pressure control is not aligning with her concern regarding pain. You tell her that you understand that the pain is her main problem, but that you are still concerned about her blood pressure. You ask her to recall your conversation at her last visit, and review what she knows about high blood pressure. She says that she remembers that it can lead to heart problems and stroke. You acknowledge that she is correct and emphasize that treatment prevents these problems; you ask whether she is willing to address both problems at this time, and she agrees. Thus, you prioritize addressing the back pain and develop a pain management plan. You ask her what barriers she sees to improving her blood pressure. She says that her main concern is avoiding the cost of adding another medication. You agree not to do so and discuss trying to improve blood pressure control through exercise. You have achieved agreement from Mrs. K. that her higher blood pressure is a problem, and she agrees to try to cut back on her salt intake and walk more in the morning. You schedule a follow-up appointment in a month.

\section{INTEGRATING MOTIVATIONAL INTERVIEWING AND SHARED DECISION-MAKING}

In a recent manuscript ${ }^{70}$ Elwyn et al. present a model that integrates the concepts of SDM and MI. Practitioners may benefit from using both approaches to help individuals consider options for medication management. MI and SDM are inherently dependent on communications skills to develop trust, understanding, and empathy, and to facilitate decisionmaking and subsequent behavioral change. These aims are 
accomplished through reflective listening, sharing of information, and responding to emotions. ${ }^{70}$

\section{SPECIFIC ROLES OF THE PROVIDER AND HEALTH SYSTEM IN SUPPORTING MEDICATION ADHERENCE THROUGH PERSON-CENTERED APPROACHES}

Healthcare providers have an important, yet largely unrealized, opportunity to participate in a person-centered approach to support their patients' use of medications. A provider's role begins with an assessment of adherence for each patient. Providers need to be familiar with risk factors for non-adherence, as well as proven strategies to improve adherence and to tailor interventions to individual patients' needs. ${ }^{71}$ Some practical approaches include:

- Anticipating common patient misperceptions - for example, that a medication for a chronic condition can be stopped when the prescription runs out, or that medications should be taken only when symptoms arise

- Considering the cost of medications

- Minimizing the complexity of treatment regimens (oncedaily dosing and appropriate combination drugs)

- Reducing polypharmacy ${ }^{72}$

- Using positive reinforcement-providers should offer congratulations if they find that the patient is following the treatment plan

- Abandoning the notion that asking about common side effects will cause the patient to start experiencing them; patients are often reluctant to raise concerns about their treatment unless asked, and side effects can be a barrier $^{73-75}$

The provider is central to achieving buy-in, keeping treatment regimens simple and focused, and evaluating improvement. The healthcare system also serves to support an environment where all of the stakeholders can provide support mechanisms to improve patient care, outcomes, and satisfaction. ${ }^{76}$ Ultimately, the healthcare system needs to support the patient and provider team across the continuum of care. For example, helpful interventions for patients with low health literacy include designing and offering easy-to-understand health educational materials and chronic disease management programs, improving medication drug labeling, and offering and incentivizing communication training for clinicians. ${ }^{77}$

\section{THE ROLE OF HEALTH TEAMS IN OPTIMAL MEDICATION USE}

Findings from a recent review suggest that adherence interventions using a team approach are effective in improving cardiovascular medication adherence, ${ }^{78}$ with a growing body of literature supporting a nurse/physician ${ }^{79}$ or pharmacist/phy$\operatorname{sician}^{79,80}$ team approach. The essential feature of the patientcentered medical home $(\mathrm{PCMH})$ is retaining the primacy of an ongoing relationship between patients and their primary care providers, although this relationship has been expanded to include other members of a core team (e.g., clerks, nurses) with whom the patient and provider have an ongoing relationship. Additional providers including dieticians and other clinical support staff can complete the team, depending on the patient's needs. The approach is proactive, both in rigorously assessing risk factors and health issues and in addressing those that are known. ${ }^{81}$ One goal of the PCMH model is to remove barriers (e.g., physical, temporal, financial) between the patient and healthcare team. This requires an open-scheduling system, an electronic health record that supports communication between team members and the patient, delegation of tasks among team members, enhanced use of non-face-toface care, and integration of clinical data. When implemented well, PCMH can improve quality of care and patient and provider satisfaction. ${ }^{81,82}$

\section{PUTTING IT ALL TOGETHER: PERSON-CENTERED APPROACHES TO APPROPRIATE MEDICATION USE}

Using a case study, we have highlighted person-centered approaches for evaluating and supporting medication adherence. Underlying this process is fundamental communication between the patient and provider. Aspects of this personcentered approach include agreeing on the problem(s) and prioritizing. In this case study, it would have been challenging to focus solely on poor blood pressure control without considering the competing problems of pain and depression and related barriers to blood pressure control. Once the provider and individual agree on the issue, diagnosis, and treatment, setting attainable goals should occur.

Generating options. is often a helpful method. There is more than one diet for losing weight, and there is more than one drug to treat hypertension. Acknowledging this fact gives the patient an opportunity to be involved in his or her care. This includes reviewing a reasonable range of treatment options, discussing the benefits and possible side effects of each in terms the patient can understand, and then asking the patient what he/she thinks might work.

Decide on a mutually agreeable and measurable regimen. Provider and patient can choose a medical option that makes sense in the patient's life. For example, the patient with hypertension may have just remarried and does not want a low-cost drug that could reduce sexual drive. She may opt for a high-cost product with no sexual side effects. Dosage frequency requires a similar discussion. Once-a-day drugs can improve adherence because they simplify dosage; however, they could discourage low-income patients from filling their prescriptions if they are more expensive than a multiple-dose version of the same agent. Some may be better off with a less 
expensive, three-times-a-day version. In many instances, adherence hinges both on the patient and on his or her family.

Understand a patient's knowledge. Consider having the patient repeat what they have been told about their illness and treatment plan. You can say, "Tell me what you understand about your illness." Likewise, ask them to explain their treatment plan, just as if they were talking to their spouse. It is also important for patients to demonstrate any techniques they have been taught, such as injecting insulin or using a peak flow meter.

Screen for readiness. One may consider two final questions at the end of an encounter to ensure that the patient's goals and values are addressed. The first is, "How important do you think it is for you to do the things we've been talking about?" The provider might discover, for example, that Mrs. K. is convinced that her disease will kill her as it did her mother, and that any treatment is futile. The provider will need to talk more about the disease and its management if a belief of this type surfaces. Another question to consider is, "On a scale of 1 to 10 , how confident are you that you can adhere to this treatment regimen?" Mrs. K., who is absolutely convinced that her hypertension medication does not work, may have a confidence level of 1 that she can actually do so, thus indicating that more counseling and support may be needed (Clinical Scenario 4).

\section{CLINICAL SCENARIO 5. RESOLUTION}

After answering her questions, you ask Mrs. K. to repeat the information back to you. In addition, you ask whether you may explain the regimen to her husband/other family member/ caregiver. Finally, you provide a written reminder with pictures describing when each medication should be taken and suggest she display this at home as another tool to serve as a reminder. You ask her to explain what the recommended regimen is and ask her how confident she is with maintaining her treatment regimen.

For the next 2 weeks a clinic nurse will call Mrs. K. once a week to determine whether she is taking the right medications at the right time and to check on her home blood pressure values. Mrs. $\mathrm{K}$. is encouraged to contact the clinic with any questions or concerns.

In summary, given the continued problems of medication adherence and associated costs and the complexity of the problem, further thought and attention to person-centered approaches are needed. Often our clinical priority may not be as important to the patient as social, psychological, or other clinical comorbidities that need to be addressed and reconciled within an overall treatment plan. We provide recommendations for how healthcare providers and teams can improve health communication by employing clear person-centered communication techniques that confirm and reinforce patient understanding and seek to improve medication adherence.

Recommendations for Providers on Person-Centered Approaches to Assess and Improve Medication Adherence

Provider

- Clarify objectives of therapy

- Ensure that the patient's decision reflects their goals and preferences

- Screen for missed appointments

- Engage the patient and ask them to describe their medication regimen,

such as when they take their medication and what the medication is for

- Use of communication skills (e.g., motivational interviewing, 5 A's

model)

- Define and explain the problem

- Present options

- Discuss pros and cons (e.g., benefits, risks, costs)

- Elicit information regarding patient's values and preferences

Examine individual's readiness to change

- Explore patient's self-efficacy

- Anticipate and avoid common patient misperceptions

- Offer recommendations

- Check and clarify patient understanding

- Move or defer a decision, if needed, and arrange follow-up

Patient

- Understand knowledge, beliefs, and attitudes about treatment

- Determine ability to attain therapeutic goals

- Ask providers to explain the therapeutic options in order to make decisions concordant with goals and preferences

- Articulate personal goals and preferences

- Set and manage expectations of the treatment plan

Healthcare system

- Support for training in motivational interviewing, and shared decisionmaking

- Provide evidence-based shared decision-making support tools

- Use information technology to help educate and support their patients

- Support the patient and provider team across the continuum of care

Acknowledgments: Dr. Bosworth is supported by a VA Health Services Research and Development (VA HSR\&D) Research Career Scientist award (RCS 08-027). Dr. Zullig is supported by a VA Health Services Research and Development (HSR\&D) Career Development Award (CDA 13-025). The content of this manuscript is solely the responsibility of the authors and does not necessarily reflect the position or policy of Duke University, the U.S. Department of Veterans Affairs, or the U.S. government.

Corresponding Author: Hayden B. Bosworth, PhD; School of Nursing and Department of PsychiatryDuke University Medical Center, 411 West Chapel Hill Street, Suite 600, Durham, NC 27701, USA (e-mail: hayden.bosworth@duke.edu).

\section{Compliance with Ethical Standards:}

Conflict of Interest: Tracy Wang, $M D$, has been the recipient of research grants to the Duke Clinical Research Institute from AstraZeneca, Boston Scientific, Bristol-Myers Squibb, Daiichi Sankyo, Eli Lilly, Gilead Sciences, Glaxo Smith Kline, and Regeneron Pharmaceuticals, as well as consulting fees or honoraria from AstraZeneca, Eli Lilly, and Premier, Inc.; Dr. Safford has consulted for diaDexus, a company that manufactures lipid assays; Dr. Bosworth reports research funds to Duke University from Takeda, Sanofi, Johnson \& Johnson, MeadWestraco (MWV), and consulting funds from Genentech, Arkansas BC/BS, CVS, Walgreens; Stephen P. Fortmann, Maureen H. Rumptz, Jennifer Kuntz reports no potential conflicts of interest

\section{REFERENCES}

1. Feldman R, Bacher M, Campbell N, Drover A, Chockalingam A. Adherence to pharmacologic management of hypertension. Can J Public Health. 1998;89(5):I16-8.

2. Flack J, Novikov SV, Ferrario CM. Benefits of adherence to antihypertensive drug therapy. Eur Heart J. 1996;17(Suppl. A):16-20. 
3. Mallion JM, Baguet JP, Siche JP, Tremel F, de Gaudemaris $\mathbf{R}$. Compliance, electronic monitoring and antihypertensive drugs. J Hypertens Suppl. 1998;16(1):S75-9.

4. Haynes RB, McKibbon KA, Kanani R. Systematic review of randomised trials of interventions to assist patients to follow prescriptions for medications. Lancet. 1996;348(9024):383-6.

5. Benner JS, Glynn RJ, Mogun H, Neumann PJ, Weinstein MC, Avorn J. Long-term persistence in use of statin therapy in elderly patients. JAMA. 2002;288(4):455-61.

6. McDermott MM, Schmitt B, Wallner E. Impact of medication nonadherence on coronary heart disease outcomes. A critical review [see comments]. Arch Intern Med. 1997;157(17):1921-9.

7. DiMatteo MR. Variations in patients' adherence to medical recommendations: a quantitative review of 50 years of research. Med Care 2004;42(3):200-9.

8. Bosworth H, Voils C. Theoretical models to understand adherence. In: Bosworth H, Oddone E, Weinberger M, eds. Patient treatment adherence: concepts, interventions, and measurement. Mahwah: Lawrence Erlbaum Associates; 2006.

9. Osterberg L, Blaschke T. Adherence to medication. N Engl J Med. 2005;353(5):487-97.

10. Gellad W, Grenard J., McGlynn EA. http://adhereforhealth.org/wp content/uploads/pdf/RAND_TR765_AReviewofBarrierstoMedicationAdherenceAFrameworkforDrivingPolicyOptions.pdf. 2009.

11. Nieuwlaat R, Wilczynski $\mathbf{N}$, Navarro T, et al. Interventions for enhancing medication adherence. Cochrane Database Syst Rev. 2014;11:CD000011.

12. Viswanathan $\mathbf{M}$, Golin $\mathbf{C E}$, Jones $\mathbf{C D}$, et al. Interventions to improve adherence to self-administered medications for chronic diseases in the United States: a systematic review. Ann Intern Med. 2012.

13. Zullig LL, Peterson ED, Bosworth HB. Ingredients of successful interventions to improve medication adherence. JAMA. 2013;310(24):2611-2.

14. Kripalani S, Yao $\mathbf{X}$, Haynes RB. Interventions to enhance medication adherence in chronic medical conditions: a systematic review. Arch Intern Med. 2007;167(6):540-50.

15. Buntin MB, Burke MF, Hoaglin MC, Blumenthal D. The benefits of health information technology: a review of the recent literature shows predominantly positive results. Health Aff. 2011;30(3):464-71.

16. Cebul RD, Love TE, Jain AK, Hebert CJ. Electronic health records and quality of diabetes care. N Engl J Med. 2011;365(9):825-33.

17. van Boven JF, Stuurman-Bieze AG, Hiddink EG, Postma MJ, Vegter S. Medication monitoring and optimization: a targeted pharmacist program for effective and cost-effective improvement of chronic therapy adherence. J Manag Care Pharm. 2014;20(8):786-92.

18. Kangovi S, Mitra N, Grande D, et al. Patient-centered community health worker intervention to improve posthospital outcomes: a randomized clinical trial. JAMA Intern Med. 2014;174(4):535-43.

19. Fagerlin A, Pignone M, Abhyankar P, et al. Clarifying values: an updated review. BMC Med Inform Decis Mak. 2013;13(Suppl 2):S8.

20. Starfield B. Is patient-centered care the same as person-focused care? Perm J. 2011;15(2):63-9.

21. Ryan R, Santesso N, Lowe $\mathbf{D}$, et al. Interventions to improve safe and effective medicines use by consumers: an overview of systematic reviews. Cochrane Database Syst Rev. 2014;4:CD007768.

22. National Community Pharmacists Association. Medication Adherence in America: A National Report 2013. Alexandria, VA: National Community Pharmacists Association; 2013. [Accessed December 11, 2013]. Available from: http://www.ncpanet.org/pdf/reportcard/adherencereportcard_ abridged.pdf.

23. Hibbard JH, Peters E. Supporting informed consumer health care decisions: data presentation approaches that facilitate the use of information in choice. Annu Rev Public Health. 2003;24:413-33.

24. Zafar SY, Tulsky JA, Abernethy AP. It's time to have 'the talk': cost communication and patient-centered care. Oncology. 2014;28(6):479-80.

25. Bayne H, Neukrug E, Hays D, Britton B. A comprehensive model for optimizing empathy in person-centered care. Patient Educ Couns. 2013;93(2):209-15.

26. Sepucha KR, Borkhoff CM, Lally J, et al. Establishing the effectiveness of patient decision aids: key constructs and measurement instruments. BMC Med Inform Decis Mak. 2013;13(Suppl 2):S12.

27. Dunbar-Jacob J, Dwyer K, Dunning EJ. Compliance with antihypertensive regimen: A review of the research in the 1980s. Ann Behav Med. 1991;13(1):31-9.

28. Bosworth HB, ed. Improving Patient Treatment Adherence: A Clinician Guidebook. New York, NY: Springer, 2010.

29. Haynes RB, McDonald HP, Garg AX. Helping patients follow prescribed treatment: clinical applications. JAMA. 2002;288(22):2880-3.
30. Stephenson BJ, Rowe BH, Haynes RB, Macharia WM, Leon G. Is this patient taking the treatment as prescribed? JAMA. 1993;269(21):2779-81.

31. Prochaska JO, Velicer WF. The transtheoretical model of health behavior change. Am J Health Promot. 1997; 12(1):38-48.

32. Martins RK, McNeil DW. Review of motivational interviewing in promoting health behaviors. Clin Psychol Rev. 2009;29(4):283-93.

33. Miller WR, Rollnick S. Ambivalence: the dilemma of change. motivational interviewing. Preparing people to change addictive behavior. New York: Guilford Press; 1991.

34. Miller WR, Rollnick S. Motivational Interviewing: Prepapring people to change addictive behaviors. New York: Guilford Press; 1991.

35. Miller WR. Motivational interviewing: research, practice, and puzzles. Addict Behav. 1996;21(6):835-42.

36. Lundahl B, Moleni T, Burke BL, et al. Motivational interviewing in medical care settings: a systematic review and meta-analysis of randomized controlled trials. Patient Educ Couns. 2013;93(2):157-68.

37. Resnicow K, Jackson A, Wang $\mathbf{T}$, et al. A motivational interviewing intervention to increase fruit and vegetable intake through Black churches: results of the Eat for Life trial. Am J Public Health. 2001;91(10):1686-93.

38. Ogedegbe G, Chaplin W, Schoenthaler A, et al. A practice-based trial of motivational interviewing and adherence in hypertensive African Americans. Am J Hypertens. 2008;21(10):1137-43.

39. Kemp R, Kirov G, Everitt B, Hayward P, David A. Randomised controlled trial of compliance therapy. 18-month follow-up. $\mathrm{Br} \mathrm{J}$ Psychiatry. 1998;172:413-9.

40. Bellack AS, Bennett ME, Gearon JS, Brown CH, Yang Y. A randomized clinical trial of a new behavioral treatment for drug abuse in people with severe and persistent mental illness. Arch Gen Psychiatry. 2006;63(4):426-32.

41. West DS, Dilillo V, Bursac Z, Gore SA, Greene PG. Motivational interviewing improves weight loss in women with type 2 diabetes. Diabetes Care. 2007;30(5):1081-7.

42. Burke BL, Arkowitz H, Menchola M. The efficacy of motivational interviewing: a meta-analysis of controlled clinical trials. J Consult Clin Psychol. 2003;71(5):843-61.

43. Miller WR, Yahne CE, Moyers TB, Martinez J, Pirritano M. A randomized trial of methods to help clinicians learn motivational interviewing. J Consult Clin Psychol. 2004;72(6):1050-62.

44. Teeter BS, Kavookjian J. Telephone-based motivational interviewing for medication adherence: a systematic review. Transl Behav Med. 2014;4(4):372-81

45. Lawn S, Schoo A. Supporting self-management of chronic health conditions: common approaches. Patient Educ Couns. 2010;80(2):205-11.

46. Glasgow RE, Davis CL, Funnell MM, Beck A. Implementing practical interventions to support chronic illness self-management. Jt Comm J Qual Saf. 2003;29(11):563-74.

47. Glasgow RE, Goldstein MG, Ockene JK, Pronk NP. Translating what we have learned into practice. Principles and hypotheses for interventions addressing multiple behaviors in primary care. Am J Prev Med. 2004;27(2 Suppl):88-101.

48. Goldstein MG, Whitlock EP, DePue J. Multiple behavioral risk factor interventions in primary care. Summary of research evidence. Am J Prev Med. 2004;27(2 Suppl):61-79.

49. Jay M, Gillespie C, Schlair S, Sherman S, Kalet A. Physicians' use of the 5 As in counseling obese patients: is the quality of counseling associated with patients' motivation and intention to lose weight? BMC Health Serv Res. 2010;10:159.

50. Whitlock EP, Orleans CT, Pender N, Allan J. Evaluating primary care behavioral counseling interventions: an evidence-based approach. Am J Prev Med. 2002;22(4):267-84.

51. van Roosmalen MS, Stalmeier PF, Verhoef LC, et al. Randomized trial of a shared decision-making intervention consisting of trade-offs and individualized treatment information for BRCAl/2 mutation carriers. J Clin Oncol. 2004;22(16):3293-301.

52. Ludman E, Katon W, Bush T, et al. Behavioural factors associated with symptom outcomes in a primary care-based depression prevention intervention trial. Psychol Med. 2003;33(6):1061-70.

53. Joosten EA, DeFuentes-Merillas L, de Weert GH, Sensky T, van der Staak CP, de Jong CA. Systematic review of the effects of shared decisionmaking on patient satisfaction, treatment adherence and health status. Psychother Psychosom. 2008;77(4):219-26.

54. Fiks AG, Mayne SL, Karavite DJ, et al. Parent-reported outcomes of a shared decision-making portal in asthma: a practice-based RCT. Pediatrics. 2015.

55. Popoola J, Greene H, Kyegombe M, MacPhee IA. Patient involvement in selection of immunosuppressive regimen following transplantation. Patient Prefer Adherence. 2014;8:1705-12. 
56. Braddock CH 3rd, Edwards KA, Hasenberg NM, Laidley TL, Levinson W. Informed decision making in outpatient practice: time to get back to basics. JAMA. 1999;282(24):2313-20.

57. Street RL Jr, Gordon HS, Ward MM, Krupat E, Kravitz RL. Patient participation in medical consultations: why some patients are more involved than others. Med Care. 2005;43(10):960-9.

58. Bauer AM, Parker MM, Schillinger D, et al. Associations between antidepressant adherence and shared decision-making, patientprovider trust, and communication among adults with diabetes: diabetes study of Northern California (DISTANCE). J Gen Intern Med. 2014;29(8):1139-47.

59. Bosworth HB, Granger BB, Mendys P, et al. Medication adherence: a call for action. Am Heart J. 2011;162(3):412-24.

60. Edwards M, Davies M, Edwards A. What are the external influences on information exchange and shared decision-making in healthcare consultations: a meta-synthesis of the literature. Patient Educ Couns. 2009;75(1):37-52.

61. Elwyn G, Frosch D, Thomson R, et al. Shared decision making: a model for clinical practice. J Gen Intern Med. 2012;27(10):1361-7.

62. Tanis M. Health-related on-line forums: what's the big attraction? J Health Commun. 2008;13(7):698-714.

63. Legare F, Thompson-Leduc $\mathbf{P}$. Twelve myths about shared decision making. Patient Educ Couns. 2014;96(3):281-6.

64. Stacey D, Legare F, Col NF, et al. Decision aids for people facing health treatment or screening decisions. Cochrane Database Syst Rev. 2014;1:CD001431.

65. Haskard KB, DiMatteo MR, Heritage J. Affective and instrumental communication in primary care interactions: predicting the satisfaction of nursing staff and patients. Health Commun. 2009;24(1):21-32.

66. Legare F, Stacey $\mathbf{D}$, Briere $\mathbf{N}$, et al. A conceptual framework for interprofessional shared decision making in home care: protocol for a feasibility study. BMC Health Serv Res. 2011;11:23.

67. Legare F, Stacey D, Graham ID, et al. Advancing theories, models and measurement for an interprofessional approach to shared decision making in primary care: a study protocol. BMC Health Serv Res. 2008;8:2

68. Haggerty JL, Reid RJ, Freeman GK, Starfield BH, Adair CE, McKendry R. Continuity of care: a multidisciplinary review. BMJ. 2003;327(7425):1219-21.

69. Reeves S, Zwarenstein M, Goldman J, et al. Interprofessional education: effects on professional practice and health care outcomes. Cochrane Database Syst Rev. 2008;1:CD002213.
70. Elwyn G, Dehlendorf C, Epstein RM, Marrin K, White J, Frosch DL. Shared decision making and motivational interviewing: achieving patientcentered care across the spectrum of health care problems. Ann Fam Med. $2014 ; 12(3): 270-5$

71. World Health Organizations. Adherence to long-term therapies: evidence for action. Geneva: World Health Organization; 2003.

72. Smith SM, Wallace E, O'Dowd T, Fortin M. Interventions for improving outcomes in patients with multimorbidity in primary care and community settings. Cochrane Database Syst Rev. 2016;3:CD006560.

73. Sleath B, Roter D, Chewning B, Svarstad B. Asking questions about medication: analysis of physician-patient interactions and physician perceptions [In Process Citation]. Med Care. 1999;37(11):116973.

74. Sleath B, Tulsky JA, Peck BM, Thorpe J. Provider-patient communication about antidepressants among veterans with mental health conditions. Am J Geriatr Pharmacother. 2007;5(1):9-17.

75. Young HN, Bell RA, Epstein RM, Feldman MD, Kravitz RL. Types of information physicians provide when prescribing antidepressants. J Gen Intern Med. 2006;21(11):1172-7.

76. Mendys PZL, Burkholder R, Granger B, Bosworth HB. Medication adherence: process for implementation. Patient Prefer Adherence. 2014;8:1025-34

77. Sudore RL, Schillinger D. Interventions to improve care for patients with limited health literacy. J Clin Outcomes Manag. 2009;16(1):20-9.

78. Cutrona SL, Choudhry NK, Stedman M, et al. Physician effectiveness in interventions to improve cardiovascular medication adherence: a systematic review. J Gen Intern Med. 2010;25(10):1090-6.

79. Carter BL, Rogers M, Daly J, Zheng S, James PA. The potency of teambased care interventions for hypertension: a meta-analysis. Arch Intern Med. 2009;169(19):1748-55.

80. Carter BL, Bergus GR, Dawson JD, et al. A cluster randomized trial to evaluate physician/pharmacist collaboration to improve blood pressure control. J Clin Hypertens. 2008;10(4):260-71.

81. Reid RJ, Fishman PA, Yu O, et al. Patient-centered medical home demonstration: a prospective, quasi-experimental, before and after evaluation. Am J Manag Care. 2009; 15(9):e71-87.

82. Ko JM, Rodriguez HP, Fairchild DG, Rodday AC, Safran DG. Paying for enhanced services: comparing patients' experiences in a concierge and general medicine practice. Patient. 2009;2(2):95103. 